\title{
Evaluation of in vitro ruminal fermentation of ensiled fruit byproducts and their potential for feed use
}

\author{
Shimaa A Mousa ${ }^{1,2}$, Pradeep K. Malik ${ }^{3}$, Atul P. Kolte ${ }^{3}$, Raghavendra Bhatta ${ }^{3}$, \\ Shigemitsu Kasuga', and Yutaka Uyeno ${ }^{1, *}$
}

\author{
* Corresponding Author: Yutaka Uyeno \\ Tel: +81-265-77-1650, Fax: +81-265-77-1650, \\ E-mail: ytkuyeno@shinshu-u.ac.jp \\ ${ }^{1}$ Graduate School of Science and Technology, Shinshu \\ University, Minamiminowa 3994598, Japan \\ 2 Faculty of Veterinary Medicine, South Valley \\ University, Qena 83523, Egypt \\ ${ }^{3}$ Energy Metabolism Laboratory, ICAR-National \\ Institute of Animal Nutrition and Physiology, \\ Bengaluru 560030, India \\ ORCID \\ Yutaka Uyeno \\ https://orcid.org/0000-0001-9217-593X
}

Submitted Apr 12, 2018; Revised Apr 27, 2018; Accepted May 24, 2018
Objective: Ensiling of tannin-rich fruit byproducts (FB) involves quantitative and qualitative changes in the tannins, which would consequently change the rumen fermentation characteristics. This study aimed to evaluate whether ensiled FBs are effective in mitigating methane emission from ruminants by conducting in vitro assessments.

Methods: Fruit byproducts (grape pomace, wild grape pomace, and persimmon skin) were collected and subjected to four-week ensiling by Lactobacillus buchneri inoculant. A defined feed component with or without FB samples (both fresh and ensiled material) were subjected to in vitro anaerobic culturing using rumen fluid sampled from beef cattle, and the fermentation parameters and microbial populations were monitored.

Results: Reduced methane production and a proportional change in total volatile fatty acids (especially enhanced propionate proportion) was noted in bottles containing the FBs compared with that in the control (without FB). In addition, we found lower gene copy number of archaeal $16 \mathrm{~S}$ rRNA and considerably higher levels of one of the major fibrolytic bacteria (Fibrobacter succinogenes) in the bottles containing FBs than in the control, particularly, when it was included in a forage-based feed. However, in the following cultivation experiment, we observed that FBs failed to exhibit a significant difference in methane production with or without polyethylene glycol, implying that tannins in the FBs may not be responsible for the mitigation of methane generation.

Conclusion: The results of the in vitro cultivation experiments indicated that not only the composition but also ensiling of FBs affected rumen fermentation patterns and the degree of methane generation. This is primarily because of the compositional changes in the fibrous fraction during ensiling as well as the presence of readily fermented substrates, whereas tannins in these FBs seemed to have little effect on the ruminal fermentation kinetics.

Keywords: Fruit Byproducts; Ensiling; Methane; Tannins

\section{INTRODUCTION}

Food byproducts have been considered as reasonable and economical feed resources. Fruit byproducts (FBs), in particular, apple pomace (AP) and grape pomace (GP), have been widely evaluated as feed material $[1,2]$. Wild grape (Vitis coignetiae, VP), which is regionally planted in Japan, also generates pomace after juicing. Persimmon skin (PS, generated during the preparation of dried persimmon), which is rich in soluble crude fiber such as pectin as well as soluble carbohydrates, also seems to be an attractive energy source in feeds [3,4]. Functional rumen microbial ecosystem is indispensable for rumen homeostasis and efficient carbohydrate conversion. In particular, methane production in ruminants has attracted considerable attention in relation to its contribution to greenhouse gas effect and global warming [5]. To date, although several means have been proposed for reducing methane emissions, inno- 
vative strategies that can substantially decrease methane output from livestock without compromising production have not yet been reported, indicating the need for elaborate assessment [6,7]. Tannins, which can form complexes with microbial proteins, are currently being intensively investigated in order to optimize rumen fermentation [8]. The potential benefits of feeding FBs that contain certain amounts of tannin in the inedible parts (seed, skin, and hull) might include manipulation of the rumen microbial community to reduce methane eructation and improve feeding efficiency. Since FBs are usually aqueous and their generation is usually limited to the harvest season every year, suitable measures need to be implemented to ensure their long-term preservation, such as lactic acid fermentation (ensiling). We previously conducted fermentation experiments of various FBs (AP, GP, and PS) to compare the fermentation quality and aerobic stability by using different lactic acid bacteria (LAB) and identified some LAB species that led to the production of high-quality FB silage [9]. In addition to decreasing soluble sugar content during silage fermentation, ensiling of tannin-rich FBs might involve quantitative and qualitative changes in the tannins $[4,10]$, which would consequently change the rumen fermentation characteristics when the silage is fed to ruminants. This study aimed to evaluate whether ensiled tannin-rich FBs are effective in mitigating methane emission from ruminants by conducting in vitro assessments.

\section{MATERIALS AND METHODS}

\section{Preparation of fruits byproduct silages}

Three types of FBs (GP, VP, and PS) were obtained from different food processing factories in Nagano Prefecture, Japan. Grape pomaces were collected from different breweries after juicing of Vitis labrusca (Niagara, as GP) and Vitis coignetiae (as VP). Persimmon skin was collected from a processing plant for dried persimmon. We collected respective FB samples from each factory twice during each harvesting season in 2016, and all the FB samples were frozen immediately after collection until use. After thawing, two batches of equal amounts of each FB sample were mixed well, and proximate composition in the mixture was analyzed according to the official methods of AOAC [11]. The total extractable phenolics and condensed tannins (CTs) were determined using the method of Makkar [12]. The CT contents in the FBs were quantified as leucocyanidin equivalents as reported in previous studies [12]. The nutritional values of each FB are shown in Table 1. Before ensiling, the water content of the PS samples was adjusted by the addition of corn cobs to $95 \mathrm{~g} / \mathrm{kg}$ dry matter (DM) PS. As in our previous study, we used Lactobacillus buchneri (L. buchneri) NBRC107764 for fermentation in this study $[9,13]$. Stock culture of this strain was used for inoculation of FB (1\% $\mathrm{v} / \mathrm{w})$. The inoculated material was mixed well by hand, and
Table 1. Proximate composition of fruit byproducts (fresh matter) and feeds used for in vitro cultivation experiment

\begin{tabular}{lccccc}
\hline Items & GP & VP & PS & Concentrate & $\begin{array}{c}\text { Italian } \\
\text { ryegrass }\end{array}$ \\
\hline DM (g/kg) & 335 & 445 & 251 & 931 & 905 \\
CP (g/kg DM) & 95 & 145 & 45 & 180 & 95 \\
NDF (g/kg DM) & 250 & 340 & 220 & 220 & 680 \\
NFC (g/kg DM) & 495 & 448 & 735 & 405 & 85 \\
TEPH (g/kg DM) & 113 & 103 & 210 & NA & NA \\
CT (g/kg DM) & 71 & 59 & 85 & NA & NA \\
\hline
\end{tabular}

$G P$, grape pomace; $V P$, wild grape pomace; $P S$, persimmon skin; DM, dry matter; $C P$, crude protein; NDF, neutral detergent fiber; NFC, non-fiber carbohydrates; TEPH, total extractable phenolics; NA, not available; $\mathrm{CT}$, condensed tannins.

$50 \mathrm{~g}$ of each was packed in a three-layer film bag. The bags were vacuum packed and tightly heat sealed (SQ-205S; Asahikasei Packs Co. Ltd., Tokyo, Japan), and then incubated at $25^{\circ} \mathrm{C}$. Ensiled content was diluted by the addition of $180 \mathrm{~mL}$ of saline to the bags and incubated for $2 \mathrm{~h}$ at $5^{\circ} \mathrm{C}$. The diluted sample was used to determine the $\mathrm{pH}, \mathrm{LAB}$ counts (by using MRS agar [Oxoid, Basingstoke, UK]), yeast counts (by using chloramphenicol-added potato dextrose agar), and organic acids (by using HPLC as described previously [13]). The FBs ensiled for 28 days were then screened for their rumen fermentation modulation ability by using the in vitro culture method. All samples were air-dried at $60^{\circ} \mathrm{C}$, ground, passed through a $1 \mathrm{~mm}$ screen, and stored at $-20^{\circ} \mathrm{C}$ until they were used for the in vitro culture test.

\section{In vitro fermentation test}

The method of incubation was the same as that used in our previous study [14]. Rumen fluid samples were collected from Japanese Black beef cows via a rumen fistula immediately before the morning feeding. Animal handling was performed according to the Shinshu University guidelines. The cows were fed Italian ryegrass straw and commercial concentrate at a 1:1 ratio. The collected rumen fluid was strained through four layers of cheesecloth and diluted (1:2) with pre-warmed McDougall buffer, which had been flushed with $\mathrm{CO}_{2}$ gas, and then used within $2 \mathrm{~h}$ after collection. The diluted rumen fluid (40 $\mathrm{mL}$ ) was dispensed into a $100 \mathrm{~mL}$ serum bottle containing substrate $(1.0 \mathrm{~g})$, and then was flushed again with $\mathrm{CO}_{2}$ gas. Experimental substrates were prepared as follows: in Experiment 1 , for each of the two types of basal feed mixture (concentratebased and forage-based, including $80 \%$ of a designated part and $20 \%$ of the remaining part), fresh FBs that were maintained at $-20^{\circ} \mathrm{C}$ (FRE), ensiled FB (SIL), or the basal feed (CONT) was included at one-third the level of the total DM. The concentrate was a commercial product and the forage was dried Italian ryegrass (Table 1). In Experiment 2, a forage-based feed was mixed with FRE, SIL, or CON to one third of total DM; subsequently, each feed mixture was subdivided into two, 
one of which included polyethylene glycol (PEG; $200 \mathrm{mg} / \mathrm{g}$ feed; PEG-6000; Wako Pure Chemical Industries Ltd., Osaka, Japan) as a tannin binder. The PEG was added to determine the effects of tannin on in vitro methanogenesis $[2,15]$. Because of material availability, Experiment 2 was performed using only GP and PS samples. The serum bottles $(n=3$ per group) were sealed with a butyl rubber stopper and aluminum cap, and then incubated anaerobically for $24 \mathrm{~h}$ at $39^{\circ} \mathrm{C}$ with shaking at $180 \mathrm{rpm}$ in a water bath.

\section{Sample analysis}

After incubation, fermentation parameters (headspace gas composition, organic acid content, and methane generation) were analyzed according to the methods described previously $[16,17]$. The total bacterial numbers, methanogens, and fibrolytic bacteria were quantified using a real-time polymerase chain reaction method. Genomic DNA of the microorganisms was extracted using the QIAamp DNA Stool Mini Kit (Qiagen, Hilden, Germany) according to the manufacturer's protocol, and the nucleic acid material was stored at less than $-20^{\circ} \mathrm{C}$ until analysis. The polymerase chain reaction (PCR) conditions and primer sequences for total bacteria, Archaea, Fibrobacter succinogenes, and Ruminococcus flavefaciens were following a previous literature $[18,19]$. Primer sets for the real-time PCR were Eub338F (ACTCCTACGGGAGGCAG) and Eub522R (ACGTCRTCCMCNCCTTCCTC) for total bacteria, qmcrAF (TTCGGTGGATCDCARAGRGC) and qmcrA-R (GBAR GTCGWAWCCGTAGAATCC) for Archaea, Fsuc3F (GTTC GGAATTACTGGGCGTAAA) and Fsuc3R (CCCCCGGAC ACCCAGTAT) for F. succinogenes, and RumFla3F (TGGCGG ACGGGTGAGTAA) and RumFla3R (TTACCATCCGTTTC CAGAAGCT) for R. flavefaciens. CFX96 Real-Time system (Bio-Rad Inc., Hercules, CA, USA) and a SYBR(R) Premix Ex Taq Kit (Takara Bio Inc., Otsu, Japan) were applied for the real-time PCR. The cycling conditions were initial denaturation at $95^{\circ} \mathrm{C}$ for $10 \mathrm{~s}$, and 40 cycles at $95^{\circ} \mathrm{C}$ for $5 \mathrm{~s}, 62^{\circ} \mathrm{C}$ for $30 \mathrm{~s}$, followed by melting curve analysis to confirm that expected PCR products were obtained.

\section{Statistical treatment}

Analysis of variance (ANOVA) was applied for each measurement in each experiment. The following model was used:

$$
\mathrm{Y}_{\mathrm{ijk}}=\mu+\alpha_{\mathrm{i}}+\beta_{\mathrm{j}}+\gamma_{\mathrm{k}}+(\alpha \beta)_{\mathrm{ij}}+(\beta \gamma)_{\mathrm{jk}}+(\gamma \alpha)_{\mathrm{ki}}+(\alpha \beta \gamma)_{\mathrm{ijk}}+\mathrm{e}_{\mathrm{ijk}}
$$

Where $Y_{\mathrm{ijk}}=$ observations for dependent variables; $\mu=$ overall mean; $\alpha_{\mathrm{i}}=$ the fixed effect of FB material (GP, VP, PS); $\beta_{\mathrm{j}}$ $=$ the fixed effect of replacement (CONT, FRE, SIL); $\gamma_{\mathrm{k}}=$ the fixed effect of base-feed (CONC, FOR; Experiment 1) or PEG inclusion (Experiment 2); $(\alpha \beta)_{\mathrm{ij}},(\beta \gamma)_{\mathrm{jk}},(\gamma \alpha)_{\mathrm{ki}},(\alpha \beta \gamma)_{\mathrm{ijk}}=$ the interaction effect; and $\mathrm{e}_{\mathrm{ijk}}=$ the residual error. Prior to ANOVA, our model assumptions were subjected to both a robust test for equality of variances, and Shapiro-Wilk's test for normality of residual data to check validity of the model. A value of $\mathrm{p}<$ 0.05 on least-squares means was considered to indicate a significant effect of the treatment. Tukey's pairwise comparison was applied for post-hoc test. All statistical analyses were performed with Stata 13.1 (Stata Corp, College Station, TX, USA).

\section{RESULTS AND DISCUSSION}

\section{Quality of ensiled FBs}

Developing tannin-rich FBs for feed use requires appropriate management to obtain high-quality silage without causing nutritional losses by aerobic deterioration. The fermentation data of the FBs are shown in Table 2. After 28 days of fermentation, the addition of LAB did not further decrease the $\mathrm{pH}$ compared to that in the control in GP and VP, and only lactate and acetate, but not propionate or butyrate, were detected in all the samples. However, the addition of LAB contributed to increased lactic acid fermentation in PS silage. L. buchneri is known to be effective in preventing aerobic deterioration when applied as an inoculant for ensiling plant feeds [20,21], and its use in silage preparation contributes to DM recovery [22]. We previously reported that the GP and PS ensiled with $L$. buchneri showed no temperature increase under anaerobic condition, indicating positive (i.e., preservative) effect in these silages [9]. Therefore, LAB inoculation of VP silage may have a positive effect on its storage stability even though yeast would survive in it. Indeed, we observed no aerobic deterioration for more than 10 days after opening the LAB-included VP silage, whereas slight (approximately $1^{\circ} \mathrm{C}$ ) temperature increases were found in the raw material and control silage (data not shown).

\section{Effects of replacement with FBs on the in vitro rumen fermentation}

In Experiment 1, we conducted an in vitro assessment to evaluate whether ensiled or non-ensiled FBs could be effective in modulating rumen fermentation as well as changing methanogen proportion (Table 3 ). As revealed by the volatile fatty acid (VFA) proportion, supplying any kind of FBs increased gas production and the changed the fermentation direction to propionate production as a hydrogen sink from the gen-

Table 2. Profiles of fruits byproducts and its silages tested in in vitro experiments

\begin{tabular}{lccllllll}
\hline \multirow{2}{*}{ Item } & \multicolumn{2}{c}{ GP } & & \multicolumn{2}{c}{ VP } & & \multicolumn{2}{c}{ PS } \\
\cline { 2 - 3 } \cline { 8 - 9 } \cline { 8 - 9 } & FRE & SIL & & FRE & SIL & & FRE & SIL \\
\hline pH & 3.86 & 3.89 & & 3.55 & 3.46 & & 6.04 & 3.54 \\
LAB (log (FU/g) & 5.15 & 6.86 & & 5.75 & 6.21 & & 5.69 & 7.86 \\
Yeast (log (FU/g) & 7.49 & 6.02 & & 6.11 & 6.12 & & 6.81 & 1.80 \\
Lactate (g/kg FM) & 15.0 & 14.7 & & 14.7 & 21.7 & & 6.3 & 38.7 \\
Acetate (g/kg FM) & 2.9 & 3.0 & & 8.5 & 9.6 & & 2.9 & 16.9 \\
\hline
\end{tabular}

GP, grape pomace; $V P$, wild grape pomace; $P S$, persimmon skin; FRE, fresh material; SIL, silage; LAB, lactic acid bacteria; CFU, colony forming units; FM, fresh matter. 
Table 3. In vitro rumen fermentation characteristics of concentrate-based or forage-based rations containing ensiled fruits byproducts

\begin{tabular}{|c|c|c|c|c|c|c|c|c|c|c|c|c|c|c|c|c|}
\hline \multirow[b]{2}{*}{ Item $^{2)}$} & \multicolumn{3}{|c|}{ Fruit } & \multicolumn{2}{|c|}{ Base feed } & \multicolumn{3}{|c|}{ Replacement } & \multirow[b]{2}{*}{ SE } & \multicolumn{3}{|c|}{ Contrasts } & \multicolumn{4}{|c|}{ Interaction } \\
\hline & $\begin{array}{l}\mathrm{GP}^{1)} \\
(18)\end{array}$ & $\begin{array}{l}V^{1)} \\
(18)\end{array}$ & $\begin{array}{l}\mathrm{PS}^{1)} \\
(18)\end{array}$ & $\begin{array}{c}\text { Concentrate }^{1)} \\
\text { (27) }\end{array}$ & $\begin{array}{l}\text { Forage }^{1)} \\
(27)\end{array}$ & $\begin{array}{l}\text { CONT }^{1)} \\
(18)\end{array}$ & $\begin{array}{l}\mathrm{FRE}^{1)} \\
(18)\end{array}$ & $\begin{array}{l}\mathrm{SIL}^{1)} \\
(18)\end{array}$ & & Fruit $(F)$ & $\begin{array}{c}\text { Base } \\
\text { feed (B) }\end{array}$ & $\begin{array}{l}\text { Replacement } \\
\text { (R) }\end{array}$ & $F \times B$ & $F \times R$ & $B \times R$ & $\mathrm{~F} \times \mathrm{B} \times \mathrm{R}$ \\
\hline Gas production $(\mathrm{mL})$ & 24.5 & 24.3 & 25.6 & 29.4 & 20.2 & 21.5 & 27.0 & 25.9 & 0.8 & 0.12 & $<0.01$ & $<0.01$ & 0.06 & 0.39 & $<0.01$ & 0.07 \\
\hline Lactate (mmol/L) & 1.3 & 1.2 & 0.7 & 0.9 & 1.1 & 1.2 & 0.9 & 0.9 & 0.1 & 0.08 & 0.45 & 0.22 & 0.25 & 0.35 & 0.40 & 0.24 \\
\hline Total VFA (mmol/L) & 85.3 & 84.2 & 89.9 & 97.6 & 75.3 & $80.6^{\mathrm{a}}$ & $93.4^{b}$ & $85.4^{\mathrm{ab}}$ & 1.9 & 0.02 & $<0.01$ & $<0.01$ & 0.02 & 0.06 & 0.26 & 0.17 \\
\hline Acetate (mol \%) & 59.3 & 59.7 & 61.0 & 56.9 & 63.1 & 63.9 & 58.8 & 57.3 & 0.7 & 0.25 & $<0.01$ & $<0.01$ & 0.46 & 0.28 & 0.03 & 0.79 \\
\hline Propionate (mol \%) & 30.1 & 30.1 & 30.4 & 32.8 & 27.6 & $27.8^{\mathrm{a}}$ & $31.2^{b}$ & $31.7^{\mathrm{b}}$ & 0.6 & 0.93 & $<0.01$ & $<0.01$ & 0.37 & 0.67 & 0.15 & 0.96 \\
\hline Butyrate (mol \%) & 10.6 & 10.2 & 8.6 & 10.3 & 9.3 & $8.3^{\mathrm{a}}$ & $10.0^{\mathrm{ab}}$ & $11.1^{b}$ & 0.4 & 0.06 & 0.18 & 0.01 & 0.37 & 0.19 & 0.11 & 0.24 \\
\hline $\mathrm{NH}_{3}-\mathrm{N}(\mathrm{mmol} / \mathrm{L})$ & 38.6 & 39.4 & 38.0 & 39.8 & 37.5 & 38.0 & 39.6 & 38.4 & 0.3 & $<0.01$ & $<0.01$ & $<0.01$ & $<0.01$ & 0.60 & $<0.01$ & 0.20 \\
\hline Methane (mmol/L) & 12.6 & 13.0 & 13.1 & 11.9 & 13.8 & 14.9 & 12.6 & 11.0 & 0.3 & 0.30 & $<0.01$ & $<0.01$ & 0.15 & 0.51 & $<0.01$ & 0.16 \\
\hline $\begin{array}{l}\text { Total bacteria } \\
\quad \text { (log } 10 \text { copies } / \mathrm{mL})\end{array}$ & 8.0 & 8.0 & 8.0 & 8.0 & 8.0 & 7.9 & 7.9 & 8.1 & 0.0 & 0.31 & 0.46 & $<0.01$ & 0.19 & 0.27 & $<0.01$ & 0.40 \\
\hline $\begin{array}{l}\text { Archaea } \\
\quad(\log 10 \text { copies } / \mathrm{mL})\end{array}$ & 6.2 & 6.2 & 6.2 & 6.2 & 6.2 & 6.2 & 6.2 & 6.1 & 0.0 & 0.98 & 0.19 & 0.01 & 0.82 & 0.65 & $<0.01$ & 0.12 \\
\hline $\begin{array}{l}\text { Archaea } \\
\text { (\% total bacteria) }\end{array}$ & 1.5 & 1.7 & 1.9 & 1.6 & 1.7 & $2.2^{\mathrm{a}}$ & $1.8^{\mathrm{b}}$ & $1.1^{c}$ & 0.1 & 0.10 & 0.23 & $<0.01$ & 0.40 & 0.35 & 0.06 & 0.09 \\
\hline
\end{tabular}

GP, grape pomace; VP, wild grape pomace; PS, persimmon skin, FRE, fresh material; SIL, silage; SE, standard error; VFA, volatile fatty acids.

1) Numbers in parenthesis indicate number of cultivation bottles in the experiment.

${ }^{a b c}$ Values with different superscripts within the same row mean significant difference. When the interaction was significant, Tukey's pairwise comparison was applied for each combination as a postestimation. Results of pairwise comparisons were shown in Supplementary Table S1 and S2.

eration of methane. Moreover, total VFA was likely increased with the FB supplementation, but according to postestimation results of the interaction between fruits and base feed (Supplementary Table S1), the effect was only significant when PS was applied, presumably because of the higher soluble sugar concentration in PS. Interestingly, concurrent results were obtained in the increase of gas production and the decrease of acetate proportion in response to addition of either type of $\mathrm{FB}$ (fresh material or ensiled one) to concentrate-based feed, whereas these results were marginally observed only with the addition of fresh material to forage-based feed. Increase in gas production (i.e., fermentation intensity) in response to addition of fresh material is probably due to fermentable sugars in the FB. On the other hand, we speculate that there may be different microbes responsible for FB fermentation according to its status (fresh material or ensiled one) since different results were obtained with respect to the base feed. Methane production was significantly decreased in response to FB supplementation when it was added to forage-based feed. Interestingly, the proportion of archaea to total bacteria was the lowest in SIL, and significantly lower in FRE than in CONT. This was due to the increase in total bacterial number in SIL within forage-based feed rather than decreasing archaeal population. As compared with fresh FBs, the ensiled ones showed no effect on other measurements, except for marginal difference in $\mathrm{NH}_{3}-\mathrm{N}$.

We hypothesized that the effects of replacement of feed with ensiled FBs on the in vitro rumen fermentation patterns were also probably because of the changes in the form of tannins during fermentation. FBs generally include non-edible parts of agricultural products, which often contain phenolic compounds such as tannins. The extractable phenolic compounds were marginally higher in PS than in GP, whereas CT levels were similar between the two FBs (Supplementary Table S3). This suggested that phenolic compounds other than CT, such as hydrolyzable tannin, were higher in PS than in GP, consistent with the findings of a previous study [23]. Antimethanogenic activities of tannins have been extensively revealed in several in vitro and in vivo studies [24,25], although not completely. We also evaluated the effects of six commercially available natural sources of tannins on the total archaea by conducting in vitro culture experiments and found that CTs reduced methane production by $5.5 \%$ and suppressed the population of methanogenic archaea by $12.0 \%$ [15]. The total archaeal population was lower when the combination of two types (hydrolyzed and $\mathrm{CTs}$ ) was used than when hydrolyzed tannins were used alone, which might be attributed to the different modes of action of these kinds of tannins.

We assumed that, in addition to tannin, the characteristics of carbohydrate composition in these FBs might also primarily determine the fermentation patterns of the in vitro rumen culture. Compared to other plant materials that are rich in tannin, inclusion of highly digestible carbohydrates with a certain amount may be a particular nature of FBs. The NFC can be immediately digested by the major members of the rumen flora (e.g., Bacteroidetes and Firmicutes) [26], and anaerobic conversion into organic acids such as succinate, propionate, and butyrate can function as an alternative hydrogen sink to methane. Theoretically, since carbohydrates available for anaerobic digestion in the in vitro culture in ensiled FBs included a greater amount of fiber than that in fresh FBs, intensive fiber digestion by fiber-degrading bacteria might occur resulting in the increased production of acetate accompanied with hydrogen, which was used for the reduction of $\mathrm{CO}_{2}$ to methane 
generation. However, the amount of methane production was higher in FRE than in SIL. Conversely, as shown recently, digestibility can be improved by ensiling total mixed ration (TMR) in an in vivo digestibility assessment $[27,28]$, which was possibly associated with enhanced fiber digestion in the rumen. We observed that ensiled TMR resulted in more methane production under in vitro rumen cultivation than fresh (non-ensiled) TMR [29]. Thus, ensiling of FBs might induce changes in the fiber composition, which would in turn offer favorable conditions for the growth of these fibrolytic bacteria.

Therefore, we performed additional in vitro cultivation experiment to evaluate in detail the relationship between the compositional changes in FBs during ensiling and the rumen fermentation characteristics and microbial profiles involved in fermentation (Experiment 2). In this experiment, we chose a forage-based feed component for the testing because it exhibited more prominent reduction than did the concentratebased one in methane generation in response to FB addition. In accordance with the previous experiment, in Experiment 2 a marginal decrease in methane production was observed between the FRE and SIL groups (Table 4). Inclusion of ensiled FBs (SIL) changed the carbohydrate profiles of the test feeds during cultivation experiments compared to those in the control (CTL, no FB addition) and even to those of FRE (Supplementary Table S3). In SIL group, the fraction of non-fiber carbohydrates (NFC) was marginally lower than that in FRE. This suggested that bacteria contributing to silage fermentation (e.g., Lactobacillus species) utilized these readily available carbohydrates to convert to lactate and acetate. In contrast, with the inclusion of NDF, overall carbohydrate composition was different between GP and PS. These compositional changes seemed to certainly affect the microbial proportions during in vitro cultivation, especially for the two representative fibrolytic bacteria. We assumed that partially degraded fiber generated from ensiling provided more suitable fermentation substrates for Fibrobacter than for Ruminococcus, and the difference in the bacteria that participated in fiber degradation might have resulted in switching the fermentation product to limited hydrogen generation, which was expected to reduce methane production. This idea is partly supported by results obtained from Experiment 2, because the absolute number of Fibrobacter was higher in the PS group than in the GP group. However, determining fermentation kinetics in the rumen is seemingly insufficient owing to the monitoring of limited microbiota. A comprehensive assessment of the microbiota with the pyrosequencing approach will enable us to understand what is changing in the rumen in response to the intervention.

The results of Experiment 2 implied that mitigation of methane production could be partly attributed to tannins. However, because we observed that two kinds of FBs failed to exhibit a significant difference in any parameter with or without PEG, except for total gas production and the interaction of the replacement and PEG inclusion on acetate proportion, the addition of PEG may have alleviated the adverse proportion changes in FRE and SIL as compared with CONT. This observation might suggest that tannins in FBs may have considerable

Table 4. In vitro rumen fermentation characteristics of test feeds containing ensiled fruits byproducts and PEG ${ }^{1)}$

\begin{tabular}{|c|c|c|c|c|c|c|c|c|c|c|c|c|c|c|c|}
\hline \multirow[b]{2}{*}{ Item ${ }^{2)}$} & \multicolumn{2}{|c|}{ Fruit } & \multicolumn{3}{|c|}{ Replacement } & \multicolumn{2}{|c|}{ PEG } & \multirow[b]{2}{*}{ SE } & \multicolumn{3}{|c|}{ Contrasts } & \multicolumn{4}{|c|}{ Interaction } \\
\hline & $\begin{array}{l}G^{1)} \\
(18)\end{array}$ & $\begin{array}{l}P^{1)} \\
(18)\end{array}$ & $\begin{array}{l}\text { CONT }^{1)} \\
(12)\end{array}$ & $\begin{array}{l}\text { FRE }^{1)} \\
(12)\end{array}$ & $\begin{array}{l}\mathrm{SIL}^{1)} \\
(12)\end{array}$ & $\begin{array}{l}- \text { PEG }^{1)} \\
(18)\end{array}$ & $\begin{array}{c}+ \text { PEG }^{1)} \\
(18)\end{array}$ & & $\begin{array}{c}\text { Fruit } \\
\text { (F) }\end{array}$ & $\begin{array}{c}\text { Replacement } \\
\text { (R) }\end{array}$ & $\begin{array}{c}\text { PEG } \\
(\mathrm{P})\end{array}$ & $F \times R$ & $\mathrm{~F} \times \mathrm{P}$ & $\mathrm{R} \times \mathrm{P}$ & $\mathrm{F} \times \mathrm{R} \times \mathrm{P}$ \\
\hline Gas production $(\mathrm{mL})$ & 22.6 & 23.0 & 23.4 & 22.2 & 22.8 & 21.8 & 23.8 & 0.4 & 0.51 & 0.36 & $<0.01$ & 0.99 & 0.47 & 0.24 & 0.14 \\
\hline Total VFA (mmol/L) & 92.8 & 95.8 & 97.9 & 94.0 & 91.0 & 93.9 & 94.7 & 1.2 & 0.25 & 0.11 & 0.76 & 0.92 & 0.97 & 0.38 & 0.93 \\
\hline Acetate (mol \%) & 52.8 & 50.5 & 55.3 & 50.5 & 49.2 & 51.3 & 52.0 & 0.9 & 0.11 & $<0.01$ & 0.21 & 0.50 & 0.93 & $<0.01^{2)}$ & 0.55 \\
\hline Propionate (mol \%) & 34.6 & 35.0 & 33.3 & 35.5 & 35.6 & 34.9 & 34.7 & 0.5 & 0.83 & 0.16 & 0.73 & 0.38 & 0.70 & 0.07 & 0.57 \\
\hline Butyrate (mol \%) & 12.6 & 14.5 & $11.4^{\mathrm{a}}$ & $14.1^{b}$ & $15.3^{b}$ & 13.8 & 13.3 & 0.6 & 0.07 & 0.01 & 0.18 & 0.80 & 0.81 & 0.07 & 0.76 \\
\hline $\mathrm{NH}_{3}-\mathrm{N}(\mathrm{mmol} / \mathrm{L})$ & 38.6 & 40.6 & 39.9 & 37.5 & 41.3 & 39.5 & 39.6 & 0.6 & 0.13 & 0.06 & 0.91 & 0.69 & 0.51 & 0.28 & 0.88 \\
\hline Methane (mmol/L) & 13.1 & 13.8 & $15.1^{\mathrm{a}}$ & $13.2^{b}$ & $12.1^{c}$ & 13.6 & 13.4 & 0.2 & 0.14 & $<0.01$ & 0.32 & 0.84 & 0.13 & 0.57 & 0.62 \\
\hline $\begin{array}{l}\text { Total bacteria } \\
\qquad(\log 10 \text { copies } / \mathrm{mL})\end{array}$ & 8.1 & 8.1 & 8.0 & 8.1 & 8.2 & 8.1 & 8.2 & 0.0 & 0.94 & 0.08 & 0.52 & 0.77 & 0.83 & 0.42 & 0.87 \\
\hline $\begin{array}{l}\text { Archaea } \\
\qquad(\log 10 \text { copies } / \mathrm{mL})\end{array}$ & 6.2 & 6.1 & 6.2 & 6.1 & 6.1 & 6.1 & 6.2 & 0.0 & 0.73 & 0.33 & 0.20 & 0.68 & 0.95 & 0.99 & 0.91 \\
\hline $\begin{array}{l}\text { Archaea } \\
\text { (\% total bacteria) }\end{array}$ & 1.3 & 1.4 & $1.8^{\mathrm{a}}$ & $1.4^{\mathrm{ab}}$ & $0.9^{b}$ & 1.5 & 1.2 & 0.1 & 0.60 & 0.03 & 0.40 & 0.77 & 0.35 & 0.17 & 0.93 \\
\hline $\begin{array}{l}\text { Fibrobacter } \\
\qquad(\log 10 \text { copies } / \mathrm{mL})\end{array}$ & 6.4 & 6.6 & $6.4^{\mathrm{a}}$ & $6.5^{\mathrm{a}}$ & $6.7^{b}$ & 6.5 & 6.5 & 0.0 & 0.04 & $<0.01$ & 0.93 & 0.10 & 0.63 & 0.54 & 0.09 \\
\hline $\begin{array}{l}\text { R. flavefaciens } \\
\quad(\log 10 \text { copies } / \mathrm{mL})\end{array}$ & 5.3 & 5.4 & 5.4 & 5.3 & 5.3 & 5.4 & 5.3 & 0.0 & 0.44 & 0.67 & 0.18 & 0.59 & 0.96 & 0.12 & 0.59 \\
\hline
\end{tabular}

PEG, polyethylene glycol; GP, grape pomace; PS, persimmon skin; CONT, basal feed; FRE, fresh material; SIL, silage; -PEG, without polyethylene glycol; +PEG, with polyethylene glycol; SE, standard error; VFA, volatile fatty acids.

1) Numbers in parenthesis indicate number of cultivation bottles in the experiment.

${ }^{2)}$ The result of postestimation showed that the following pairs were significantly different $(p<0.01)$ : (CONT-PEG) vs (FRE-PEG), (CONT-PEG) vs (SIL-PEG), (CONT-PEG) vs (SIL+PEG), (CONT+PEG) vs (FRE-PEG), and (FRE-PEG) vs (FRE+PEG).

${ }^{a b c}$ Values within the row with different superscripts are significantly different $(p<0.05)$ 
effect on changes in fermentation pattern in the rumen owing to some minor modifications of rumen microbe composition. However, it cannot be responsible for the mitigation of methane production as this effect seemed to depend largely on the carbohydrate profile of the FBs. Owing to the differences between hydrolyzed tannin and CT in terms of effects on fermentation in the rumen, determining the protein binding capacity of tannins present in FBs might be important for assessing the extent to which they would affect rumen microbes [30]. The finding that no significant effects of tannins on methane generation were observed may be mostly attributed to the limited amount of FB inclusion (one-third to total DM), which was aimed at practical implementation.

\section{CONCLUSION}

The results of the in vitro cultivation experiments indicated that not only the composition but also ensiling of FBs affected rumen fermentation patterns and the degree of methane generation in in vitro culture. Our results suggested that ensiled FBs could initially have some direct or indirect effects on the reduction of methanogens. This is primarily because of the compositional changes in the fibrous fraction during ensiling as well as the presence of readily fermented substrates, whereas tannins in these FBs seemed to have little effect on the in vitro ruminal methane generation. Animal feeding experiments are warranted to determine whether feeding FBs increases feed efficiency owing to the improvement of fiber digestibility, or whether the effect might be offset by increasing methane emission. Detailed monitoring of the digestion kinetics of nutrients, as well as of the microbial interactions within the ecosystem by performing animal experiments might be needed for the practical application of ensiled FBs as feed for optimized rumen fermentation.

\section{CONFLICT OF INTEREST}

We certify that there is no conflict of interest with any financial organization regarding the material discussed in the manuscript.

\section{ACKNOWLEDGMENTS}

This work was financially supported by India-Japan Cooperative Science Programme, Mayekawa Houonkai Foundation, and the project of the NARO Bio-oriented Technology Research Advancement Institution (the special scheme project on regional developing strategy).

\section{REFERENCES}

1. Baumgärtel T, Kluth H, Epperlein K, Rodehutscord M. A note on digestibility and energy value for sheep of different grape pomace. Small Rumin Res 2007;67:302-6.

2. Abarghuei MJ, Rouzbehan Y, Alipour D. The influence of the grape pomace on the ruminal parameters of sheep. Livest Sci 2010;132:73-9.

3. Kim HY, Song YM, Jin SK, et al. The effect of change in meat quality parameters on pig Longissimus dorsi muscle by the addition of fermented persimmon shell diet. Asian-Australas J Anim Sci 2006;19:286-91.

4. Kim HY, Song YM, Kang YS, et al. The effect of fermented persimmon shell diet supplementation on the growth performance and blood parameters in finishing pigs. Anim Sci J 2006;77:3149.

5. Hristov AN, Oh J, Giallongo F, et al. An inhibitor persistently decreased enteric methane emission from dairy cows with no negative effect on milk production. Proc Natl Acad Sci USA 2015;112:10663-8.

6. Martin C, Morgavi DP, Doreau M. Methane mitigation in ruminants: from microbe to the farm scale. Animal 2010;4:35165 .

7. Uyeno Y. Selective inhibition of harmful rumen microbes. In: Puniya AK, Singh R, Kamra DN, editors. Rumen microbiology: From evolution to revolution. Berlin, Germany: Springer-Verlag $\mathrm{GmbH}$; 2015. p. 199-211.

8. AOAC (Association of Official Analytical Chemists). In: AOAC. editor. Official methods of analysis, 15th Ed. Arlington, VA, USA: AOAC International; 1990.

9. Uyeno Y, Konaka R, Shirota M, Kobayashi S. Ensiling fruit byproducts with inoculum of lactic acid bacteria strains. Anim Nutr Feed Technol 2016;16:515-9.

10. Alipour D, Rouzbehan Y. Effects of ensiling grape pomace and addition of polyethylene glycol on in vitro gas production and microbial biomass yield. Anim Feed Sci Technol 2007;137:13849.

11.NRC. Nutrient requirements of dairy cattle. 7th ed. Washington, DC, USA: National Academy Press; 2001.

12. Makkar HP. Quantification of tannins in tree and shrub foliage: a laboratory manual. Dordrecht, Netherlands: Springer; 2003.

13. Hiramori C, Uyeno Y, Koh K. Effects of lactic acid bacteria on fermented apple pomace (FAP) production and the inclusion of an FAP into a medium for bunashimeji (Hypsizygus marmoreus) cultivation. Mushroom Sci Biotechnol 2015;23:120-4.

14. Uyeno $Y$, Wang $C$, Jayanegara A, et al. Increase in rumen fibrolytic bacteria and the improvement of fiber degradability of ensiling total mixed ration assessed by in vitro rumen culture. Adv Anim Vet Sci 2016;4:183-6.

15. Bhatta R, Uyeno Y, Tajima K, et al. Difference in the nature of tannins on in vitro ruminal methane and volatile fatty acid production and on methanogenic archaea and protozoal populations. J Dairy Sci 2009;92:5512-22.

16. Abrar A, Kondo M, Kitamura T, Ban-Tokuda T, Matsui H. Effect of supplementation of rice bran and fumarate alone or 
in combination on in vitro rumen fermentation, methanogenesis and methanogens. Anim Sci J 2016;87:398-404.

17.Denman SE, Tomkins NW, McSweeney CS. Quantitation and diversity analysis of ruminal methanogenic populations in response to the antimethanogenic compound bromochloromethane. FEMS Microbiol Ecol 2007;62:313-22.

18. Lettat A, Hassanat F, Benchaar C. Corn silage in dairy cow diets to reduce ruminal methanogenesis: effects on the rumen metabolically active microbial communities. J Dairy Sci 2013;96: 5237-48.

19. Stevenson D, Weimer P. Dominance of Prevotella and low abundance of classical ruminal bacterial species in the bovine rumen revealed by relative quantification real-time PCR. Appl Microbiol Biotechnol 2007;75:165-74.

20.Tabacco E, Righi F, Quarantelli A, Borreani G. Dry matter and nutritional losses during aerobic deterioration of corn and sorghum silages as influenced by different lactic acid bacteria inocula. J Dairy Sci 2011;94:1409-19.

21. Nishino N, Wada H, Yoshida M, Shiota H. Microbial counts, fermentation products, and aerobic stability of whole crop corn and a total mixed ration ensiled with and without inoculation of Lactobacillus casei or Lactobacillus buchneri. J Dairy Sci 2004; 87:2563-70.

22. Goeser J, Heuer C, Crump P. Forage fermentation product measures are related to dry matter loss through meta-analysis. Prof Anim Sci 2015;31:137-45.

23. Kondo M, Jayanegara A, Uyeno Y, Matsui $H$. Variation of tannin contents in selected agro-industrial by-products and their bio- logical activity in precipitating protein. Adv Anim Vet Sci 2016; 4:66-70.

24. Patra AK, Saxena J. Exploitation of dietary tannins to improve rumen metabolism and ruminant nutrition. J Sci Food Agric 2011;91:24-37.

25. Malik P, Kolte A, Baruah L, et al. Enteric methane mitigation in sheep through leaves of selected tanniniferous tropical tree species. Livest Sci 2017;200:29-34.

26. Dehority BA. Numbers, factors affecting the population and distribution of rumen bacteria. In: Dehority BA, editor. Rumen microbiology. Nottingham, UK: Nottingham University Press; 2003. p. 265-94.

27. Cao Y, Takahashi T, Horiguchi K-i, Yoshida N, Cai Y. Methane emissions from sheep fed fermented or non-fermented total mixed ration containing whole-crop rice and rice bran. Anim Feed Sci Technol 2010;157:72-8.

28. Cao Y, Takahashi T, Horiguchi Ki, Yoshida N, Zhou D. In vitro ruminal dry matter digestibility and methane production of fermented total mixed ration containing whole-crop rice and rice bran. Grassl Sci 2012;58:133-9.

29. Wang C, Uyeno $\mathrm{Y}$, Jayanegara $\mathrm{A}$, et al. Changes in in vitro rumen fermentation characteristics of different compositions of total mixed rations (TMR) and the ensiled TMRs. Adv Anim Vet Sci 2016;4:179-82.

30. Jayanegara A, Togtokhbayar N, Makkar HP, Becker K. Tannins determined by various methods as predictors of methane production reduction potential of plants by an in vitro rumen fermentation system. Anim Feed Sci Technol 2009;150:230-7. 